\title{
Deaths from all causes in a long-term follow-up study of 11583 deliberate self-harm patients
}

\author{
K. HAWTON*, L. HARRISS AND D. ZAHL \\ Centre for Suicide Research, University of Oxford Department of Psychiatry, Warneford Hospital, \\ Oxford, $U K$
}

\begin{abstract}
Background. Deliberate self-harm (DSH) may be associated with increased risk of death from a variety of causes, not just suicide.

Method. A follow-up study of 11583 DSH patients who presented to a general hospital over a 20 -year period was conducted to examine risk of death from a range of causes during a follow-up period of between 3 and 23 years. Deaths were identified through national death registries. Expected numbers of deaths were calculated from national death statistics.
\end{abstract}

Results. The number of deaths $(1185,10 \cdot 2 \%)$ was $2 \cdot 2$ times the expected number, the excess being significantly greater in males than females. Suicides were 17 times more frequent than expected and undetermined causes of death and accidental poisonings 15 times more frequent. Significantly more than expected numbers of deaths from most natural causes were found, including respiratory disease, circulatory, neurological, endocrine, digestive, skin and musculoskeletal and connective tissue disorders, and symptoms, signs and ill-defined conditions. Deaths due to accidents other than poisoning were more frequent than expected in both genders and homicides more frequent in males.

Conclusions. In addition to increased risk of suicide, DSH patients are at increased risk of dying from a wide range of other causes. Possible explanations include lifestyle factors, physical disorders contributing to initial risk of DSH, and social disadvantage. The findings are relevant to clinical management and evaluation of outcome and health-care costs associated with DSH.

\section{INTRODUCTION}

An important aspect of the significance of attempted suicide or deliberate self-harm (DSH) is the extent to which it is associated with future risk of death. While the association with eventual suicide has understandably been the focus of considerable research (Hawton \& Fagg, 1988; Nordentoft et al. 1993; Sakinofsky, 2000; Hawton et al. 2003 b), much less attention has been paid to the risk of death from other causes. Yet increased risk of suicide in certain

\footnotetext{
* Address for correspondence: Professor Keith Hawton, Centre for Suicide Research, University of Oxford Department of Psychiatry, Warneford Hospital, Headington, Oxford OX3 7JX, UK.

(Email: keith.hawton@psych.ox.ac.uk)
}

physical disorders is well recognized (Harris \& Barraclough, 1994; Stenager \& Stenager, 2000). In addition, physical illnesses are relatively common in patients who attempt suicide (De Leo et al. 1999).

More than 25 years ago, Pederson et al. (1975) in the USA noted an excess death rate in suicide attempters for respiratory and neurological disorders, and accidents. In the UK, Hawton \& Fagg (1988) followed up attempted suicide patients for an average of over 8 years and similarly found an excess risk of death from these causes, but also for circulatory and endocrine disorders. In a 10-year follow-up study of Danish suicide attempters, Nordentoft et al. (1993) found more deaths than expected due 
to respiratory, neurological and digestive disorders, and also neoplasms and alcohol-related conditions. More recently, Ostamo \& Lönnqvist (2001) followed up Finnish suicide attempters for a mean of $5 \cdot 3$ years and found an excess risk of death from 'disease' and accidents, and also homicide in males.

The above studies have limitations. First, the sample sizes were relatively small in terms of examining infrequent outcomes in relation to a wide range of disease categories, increasing the probability that some association may not have been identified. Second, the follow-up periods were relatively short, with a maximum followup time for any patient of 10 years. Some important physical illnesses likely to be more common in DSH patients may not manifest themselves for many years.

We have conducted a large-scale study of a consecutive sample of DSH patients presenting to a general hospital over several years, to examine risk of death from all causes. Elsewhere we have provided details of risk of suicide by gender and age subgroups (Hawton et al. $2003 \mathrm{~b}$ ). Here we report the risk of death for all causes, focusing especially on deaths from causes other than suicide. The aim of this study was to attempt to verify over a longer follow-up period, and within a large sample of DSH patients, the risk of death from conditions for which associations have previously been highlighted in shorter follow-up studies, and to explore death rates for other conditions.

\section{METHOD}

\section{Study population}

The study sample was identified using the Oxford Monitoring System for Attempted Suicide, through which data are collected on all DSH presentations to the general hospital in Oxford, including both admitted and nonadmitted patients and those not assessed by the hospital psychiatric service as well as those who are assessed (Hawton et al. 1997, 2003 b). Thus all patients presenting with an episode of DSH are identified. The original sample consisted of 12931 patients who presented following an episode of DSH between 1 January 1978 and 31 December 1997. Most (86.8\%) of these patients $(84.4 \%$ of males and $88.4 \%$ of females) were admitted to the general hospital, and $84 \cdot 2 \%(81 \cdot 5 \%$ males, $86 \cdot 0 \%$ females $)$ were assessed by the general hospital psychiatric service.

\section{Follow-up}

The follow-up period continued until 31 December 2000. The maximum duration of follow-up was therefore 23 years. Details of all individuals (name, gender and date of birth) who presented during the study period were submitted to the Office for National Statistics (ONS) for England and Wales. Tracing revealed whether subjects were alive or deceased as of 31 December 2000. It also provided information, including the date, on those who had emigrated from England and Wales, moved to Ireland or Scotland, or left the register for other reasons. Further tracing was conducted through the Central Services Agency (Northern Ireland) and through the General Register Office for Scotland. Copies of death certificates were obtained for all subjects who had died.

The causes of death used for this study were the underlying conditions recorded on the death certificates as being the primary cause of death. ICD 9 codes (WHO, 1997) were used. All codes recorded prior to the introduction of ICD 9 were updated to ICD 9.

Follow-up until the end of the study period or death was possible for 11221 patients $(86.8 \%$ of the original sample). A further $362(2 \cdot 8 \%)$ were tracked for less than their maximum follow-up time (but included in the analysis for the duration of their follow-up periods), yielding a total of 11583 persons in the followup sample. Patients for whom no follow-up information was available at any time during the follow-up period $(1348,10 \cdot 4 \%$ ), usually because of incorrect identifier information, were excluded from the study.

\section{Analyses}

Total person-years at risk were calculated according to gender, age (5-year age bands) and calendar year.

For every cause of death of interest, the national death rate was calculated using data for England and Wales provided by the ONS, again by gender, age (5-year age bands) and calendar year. For each cause, the person-years at risk were multiplied by the national rate for each gender, age and year subgroup, to give an 
expected number of deaths within the DSH sample. The total expected number of deaths for each cause over the entire study period was determined by summing across all ages and years.

Relative risks were calculated by dividing the observed number of deaths from each cause by the expected number. Confidence intervals (CIs) for the relative risks were computed using the Poisson distribution.

We did not include deaths in the following categories: complications of pregnancy, childbirth and the puerperium; congenital abnormalities; and certain conditions originating in the prenatal period.

\section{RESULTS \\ Study sample}

The followed-up sample of 11583 patients included 6969 females and 4614 males. The methods of DSH were self-poisoning in $89.4 \%$ (10 534) of cases, self-injury in 7.6\% (879) and both methods in $3.0 \%$ (350) (method not known in one case). There was no gender difference between the followed-up patients and those who could not be followed up $\left(\chi^{2}=0 \cdot 30\right.$, $p=0.58)$. However, more of the followed-up patients were admitted to a general hospital bed because of the index episode of DSH $\left(87.7 \%\right.$ v. $\left.79 \cdot 1 \%, \chi^{2}=78 \cdot 1, p<0 \cdot 001\right)$, received a psychosocial assessment $(85 \cdot 1 \%$ v. $76 \cdot 3 \%$, $\left.\chi^{2}=69.5, p<0.001\right)$ and used self-poisoning (alone) in their DSH episodes $(89.4 \%$ v. 86.0\%, $\left.\chi^{2}=20 \cdot 6, \mathrm{df}=2, p<0 \cdot 001\right)$.

\section{Deaths}

A total of $1185(10 \cdot 2 \%)$ patients died during the follow-up period. This was more than double the expected number (Table 1). There were $624(13.5 \%)$ deaths in the males and 561 $(8.0 \%)$ in the females. The excess of deaths was significantly greater for males [odds ratio (OR) $2 \cdot 6,95 \%$ CI 2.4-2.8] than females (OR 1.9, $95 \%$ CI $1 \cdot 7-2 \cdot 0)$.

\section{Deaths from suicide and related causes}

As expected, deaths due to suicide and possible suicide (undetermined cause and accidental poisoning) were significantly more frequent than predicted from general population mortality statistics (Table 1). Suicides were 17 times more frequent than expected, with female suicides being especially frequent. Deaths from undetermined cause (open verdicts) occurred 15 times more often than expected in both genders. Accidental poisonings were also 15 times more frequent than expected, with a particularly marked excess in males. There were excess numbers of deaths from 'mental disorders' in both genders.

\section{Deaths from physical illness}

There were excess numbers of deaths from most causes, including endocrine and related conditions, neurological disorders, circulatory disease, respiratory disease, digestive system disorders, skin conditions (especially in males), musculoskeletal and connective tissue disorders (males), and symptoms, signs and ill-defined conditions (Table 1). Within endocrine disorders, diabetes was examined separately and a borderline excess number of deaths found [observed $(\mathrm{O})=12$, expected $(\mathrm{E})=6 \cdot 2, \mathrm{O} / \mathrm{E}=$ $1 \cdot 9,95 \%$ CI $1 \cdot 0-3 \cdot 4]$. There was also an excess of deaths from epilepsy $(\mathrm{O}=7, \mathrm{E}=2 \cdot 2, \mathrm{O} / \mathrm{E}=$ $3 \cdot 2,95 \%$ CI $1 \cdot 3-6 \cdot 5)$, due to an excess in males $(\mathrm{O}=5, \mathrm{E}=1 \cdot 2, \mathrm{O} / \mathrm{E}=4 \cdot 3,95 \%$ CI $1 \cdot 4-10 \cdot 1)$. No overall excess of deaths from multiple sclerosis was found $(\mathrm{O}=4, \mathrm{E}=1 \cdot 5, \mathrm{O} / \mathrm{E}=2 \cdot 6$, $95 \%$ CI $0.7-6 \cdot 8)$, although there was a marginally increased risk in females $(\mathrm{O}=4, \mathrm{E}=1 \cdot 1$, $\mathrm{O} / \mathrm{E}=3 \cdot 7,95 \%$ CI $1 \cdot 0-9 \cdot 4$ ).

We examined the deaths due to conditions likely to be related to alcohol abuse (ICD codes E303, 571 and 456.0) in terms of whether the individuals had alcohol problems at the time of their DSH episodes. Alcohol problems equated to a diagnosis of alcoholism up until mid-1988, and a diagnosis of alcohol dependence with or without physical symptoms between then and the end of 1997. Of 24 individuals who died from causes likely to be related to alcohol abuse, $13(54 \cdot 2 \%)$ had alcohol problems at the time of DSH compared with $153(16 \cdot 3 \%)$ out of 938 patients who died from other causes $\left(\chi^{2}=20.91\right.$, $p<0.001)$.

Neither the number of deaths due to neoplasms $(\mathrm{O}=173, \mathrm{E}=153 \cdot 4, \mathrm{O} / \mathrm{E}=1 \cdot 1,95 \% \mathrm{CI}$ $0 \cdot 9-1 \cdot 3)$ nor specifically those due to neoplasms affecting the lung and related structures $(\mathrm{O}=37$, $\mathrm{E}=30 \cdot 9, \mathrm{O} / \mathrm{E}=1 \cdot 2,95 \%$ CI $0 \cdot 8-1 \cdot 7)$ significantly exceeded the expected number. 
Table 1. Death by cause: observed $(O)$ and expected numbers $(E)$, by gender

\begin{tabular}{|c|c|c|c|c|c|c|c|c|c|c|c|c|c|}
\hline \multirow[b]{2}{*}{ Cause } & \multirow[b]{2}{*}{ ICD code } & \multicolumn{4}{|c|}{ Males } & \multicolumn{4}{|c|}{ Females } & \multicolumn{4}{|c|}{ Both genders } \\
\hline & & $\mathrm{O}$ & $\mathrm{E}$ & $\mathrm{O} / \mathrm{E}$ & $95 \% \mathrm{CI}$ & $\mathrm{O}$ & $\mathrm{E}$ & $\mathrm{O} / \mathrm{E}$ & $95 \% \mathrm{CI}$ & $\mathrm{O}$ & $\mathrm{E}$ & $\mathrm{O} / \mathrm{E}$ & $95 \% \mathrm{CI}$ \\
\hline Infectious and parasitic diseases & 0010-1399 & 1 & $2 \cdot 3$ & $0 \cdot 4$ & $0 \cdot 0-2 \cdot 5$ & 2 & $2 \cdot 1$ & $1 \cdot 0$ & $0 \cdot 1-3 \cdot 5$ & 3 & $4 \cdot 3$ & $0 \cdot 7$ & $0 \cdot 1-2 \cdot 0$ \\
\hline Neoplasms & $1400-2399$ & 76 & $62 \cdot 6$ & $1 \cdot 2$ & $0 \cdot 96-1 \cdot 5$ & 97 & $90 \cdot 8$ & $1 \cdot 1$ & $0 \cdot 9-1 \cdot 3$ & 173 & $153 \cdot 4$ & $1 \cdot 1$ & $0 \cdot 9-1 \cdot 3$ \\
\hline $\begin{array}{l}\text { Endocrine, nutritional and metabolic diseases and } \\
\text { immunity disorders }\end{array}$ & $2400-2799$ & 8 & $3 \cdot 7$ & $2 \cdot \overline{2}$ & $0 \cdot 9-4 \cdot 3$ & 10 & $5 \cdot 1$ & $2 \cdot 0$ & $0 \cdot 9-3 \cdot 6$ & 18 & $8 \cdot 8$ & $2 \cdot 0$ & $1 \cdot 2-3 \cdot 2$ \\
\hline Diseases of blood and blood-forming organs & $2800-2899$ & 2 & $0 \cdot 8$ & $2 \cdot 5$ & $0 \cdot 3-9 \cdot 1$ & 2 & $1 \cdot 1$ & $1 \cdot 8$ & $0 \cdot 2-6 \cdot 3$ & 4 & 1.9 & $2 \cdot 1$ & $0 \cdot 5-5 \cdot 2$ \\
\hline Mental disorders & $2900-3199$ & 15 & $4 \cdot 0$ & $3 \cdot 8$ & $2 \cdot 1-6 \cdot 2$ & 14 & $5 \cdot 6$ & $2 \cdot 5$ & $1 \cdot 4-4 \cdot 2$ & 29 & $9 \cdot 6$ & $3 \cdot 0$ & $2 \cdot 0-4 \cdot 3$ \\
\hline Diseases of the nervous system and the sense organs & $3200-3899$ & 14 & $5 \cdot 0$ & $2 \cdot 8$ & $1 \cdot 5-4 \cdot 7$ & 15 & $6 \cdot 5$ & $2 \cdot 3$ & $1 \cdot 3-3 \cdot 8$ & 29 & $11 \cdot 5$ & $2 \cdot 5$ & $1 \cdot 6-3 \cdot 6$ \\
\hline Diseases of the circulatory system & $3900-4599$ & 159 & $97 \cdot 2$ & $1 \cdot 6$ & $1 \cdot 4-1 \cdot 9$ & 168 & $114 \cdot 7$ & $1 \cdot 5$ & $1 \cdot 3-1 \cdot 7$ & 327 & 211.8 & 1.5 & $1 \cdot 3-1 \cdot 7$ \\
\hline Diseases of the respiratory system & $4600-5199$ & 71 & $28 \cdot 6$ & $2 \cdot 5$ & $1 \cdot 9-3 \cdot 1$ & 65 & $36 \cdot 0$ & $1 \cdot 8$ & $1 \cdot 4-2 \cdot 3$ & 136 & $64 \cdot 5$ & $2 \cdot 1$ & $1 \cdot 7-2 \cdot 4$ \\
\hline Diseases of the digestive system & $5200-5799$ & 30 & $3 \cdot 4$ & $3 \cdot 1$ & $2 \cdot 3-4 \cdot 9$ & 27 & $12 \cdot 1$ & $2 \cdot 2$ & $1 \cdot 5-3 \cdot 2$ & 57 & $20 \cdot 9$ & $2 \cdot 7$ & $2 \cdot 0-3 \cdot 5$ \\
\hline Diseases of the genito-urinary system & $5800-6299$ & 2 & $2 \cdot 5$ & $0 \cdot 8$ & $0 \cdot 1-2 \cdot 8$ & 8 & $3 \cdot 5$ & $2 \cdot 3$ & $0 \cdot 98-4 \cdot 5$ & 10 & $6 \cdot 1$ & $1 \cdot 6$ & $0 \cdot 7-3 \cdot 0$ \\
\hline Diseases of the skin and subcutaneous tissue & $6800-7099$ & 4 & $0 \cdot 2$ & $19 \cdot 0$ & $5 \cdot 2-48 \cdot 5$ & 3 & $0 \cdot 6$ & $5 \cdot 1$ & $1 \cdot 1-14 \cdot 8$ & 7 & 0.8 & $8 \cdot 7$ & $3 \cdot 5-17 \cdot 9$ \\
\hline $\begin{array}{l}\text { Diseases of the musculoskeletal system and } \\
\text { connective tissue }\end{array}$ & $7100-7399$ & 5 & $0 \cdot 9$ & 5.9 & $1 \cdot 9-13 \cdot 7$ & 6 & $2 \cdot 9$ & $2 \cdot 1$ & $0 \cdot 8-5 \cdot 5$ & 11 & $3 \cdot 8$ & $2 \cdot 9$ & $1 \cdot 4-5 \cdot 2$ \\
\hline Symptoms, signs and ill-defined conditions & 7800-7999 & 9 & 1.8 & $5 \cdot 1$ & $2 \cdot 3-9 \cdot 6$ & 14 & $4 \cdot 1$ & $3 \cdot 4$ & $1 \cdot 9-5 \cdot 8$ & 23 & $5 \cdot 9$ & 3.9 & $2 \cdot 4-5 \cdot 8$ \\
\hline Accidents and adverse effects other than poisoning & $\begin{array}{l}\text { E8000-8449 } \\
\text { E8700-9499 }\end{array}$ & 33 & $11 \cdot 3$ & $2 \cdot 9$ & $2 \cdot 0-4 \cdot 1$ & 21 & $6 \cdot 8$ & $3 \cdot 1$ & $1.9-4 \cdot 8$ & 54 & $18 \cdot 0$ & $3 \cdot 0$ & $2 \cdot 3-3 \cdot 9$ \\
\hline Accidental poisoning & E8500-8699 & 31 & 1.8 & $17 \cdot 2$ & $11 \cdot 7-24 \cdot 4$ & 10 & $1 \cdot 0$ & $10 \cdot 3$ & $4 \cdot 9-18 \cdot 9$ & 41 & $2 \cdot 8$ & $14 \cdot 8$ & $10 \cdot 6-20 \cdot 0$ \\
\hline Suicide and self-inflicted injury & E9500-9599 & 111 & $7 \cdot 5$ & $14 \cdot 9$ & $12 \cdot 2-17 \cdot 9$ & 66 & $3 \cdot 1$ & $21 \cdot 4$ & $16 \cdot 5-27 \cdot 2$ & 177 & $10 \cdot 6$ & $16 \cdot 8$ & $14 \cdot 4-19 \cdot 4$ \\
\hline $\begin{array}{l}\text { Homicide and injury purposely inflicted by } \\
\text { other persons }\end{array}$ & E9600-9699 & 3 & $0 \cdot 5$ & $5 \cdot 8$ & $1 \cdot 2-16 \cdot 8$ & 1 & 0.5 & $2 \cdot 2$ & $0 \cdot 1-12 \cdot 1$ & 4 & $1 \cdot 0$ & $4 \cdot 1$ & $1 \cdot 1-10 \cdot 4$ \\
\hline $\begin{array}{l}\text { Injury undetermined whether accidentally } \\
\text { or purposely inflicted }\end{array}$ & E9800-9899 & 50 & $3 \cdot 3$ & $15 \cdot 1$ & $11 \cdot 2-19 \cdot 9$ & 32 & $2 \cdot 1$ & $15 \cdot 1$ & $10 \cdot 4-21 \cdot 4$ & 82 & $5 \cdot 4$ & $15 \cdot 1$ & $12 \cdot 0-18 \cdot 7$ \\
\hline Overall & & 624 & $242 \cdot 7$ & $2 \cdot 6$ & $2 \cdot 4-2 \cdot 8$ & 561 & $298 \cdot 5$ & 1.9 & $1 \cdot 7-2 \cdot 0$ & 1185 & $514 \cdot 2$ & $2 \cdot 2$ & $2 \cdot 1-2 \cdot 3$ \\
\hline
\end{tabular}




\section{Deaths due to accidents (other than poisoning) and homicide}

Accident deaths other than poisoning were more frequent than expected in both genders (Table 1). Motor vehicle accidents (E81008199) were examined separately. There was a relative excess in deaths but this did not quite reach statistical significance $(\mathrm{O}=16, \mathrm{E}=9 \cdot 3$, $\mathrm{O} / \mathrm{E}=1 \cdot 7,95 \%$ CI $0 \cdot 98-2 \cdot 8)$. There were more homicides than expected, this excess being due to the number of males who died from homicide (Table 1).

\section{Timing of deaths following DSH}

The timing of the deaths following DSH was examined for causes where there were fairly large numbers of deaths or for those that were especially interesting in relation to suicidal behaviour. This was carried out by plotting the percentage of people dying from that cause within each year of follow-up (as a proportion of all individuals followed up in each year). Deaths due to endocrine disorders and diseases of the circulatory and respiratory systems were fairly evenly spread over the follow-up period (with a slight increase in risk over time, in keeping with increasing risk with age in the general population), whereas those due to digestive system disorders showed a fairly marked increase in risk during the second half of the overall follow-up period (Fig. 1).

Deaths due to external causes largely showed a different pattern (Fig. 2). Thus deaths that received a coroner's verdict of suicide or undetermined cause occurred most frequently during the initial part of the follow-up period (although deaths in both these categories continued to occur throughout the overall followup period). Most deaths that received a verdict of accident, whether due to poisoning or other causes, occurred during the initial few years of follow-up.

\section{DISCUSSION}

We have found that DSH patients followed up for several years have more than double $(\mathrm{O} / \mathrm{E}=2 \cdot 2)$ the risk of dying during that period compared with the general population. The risk is particularly elevated in males. This overall risk is similar to that found in $\mathrm{DSH}$ patients in Oxford in an earlier study $(\mathrm{O} / \mathrm{E}=2 \cdot 3)$,
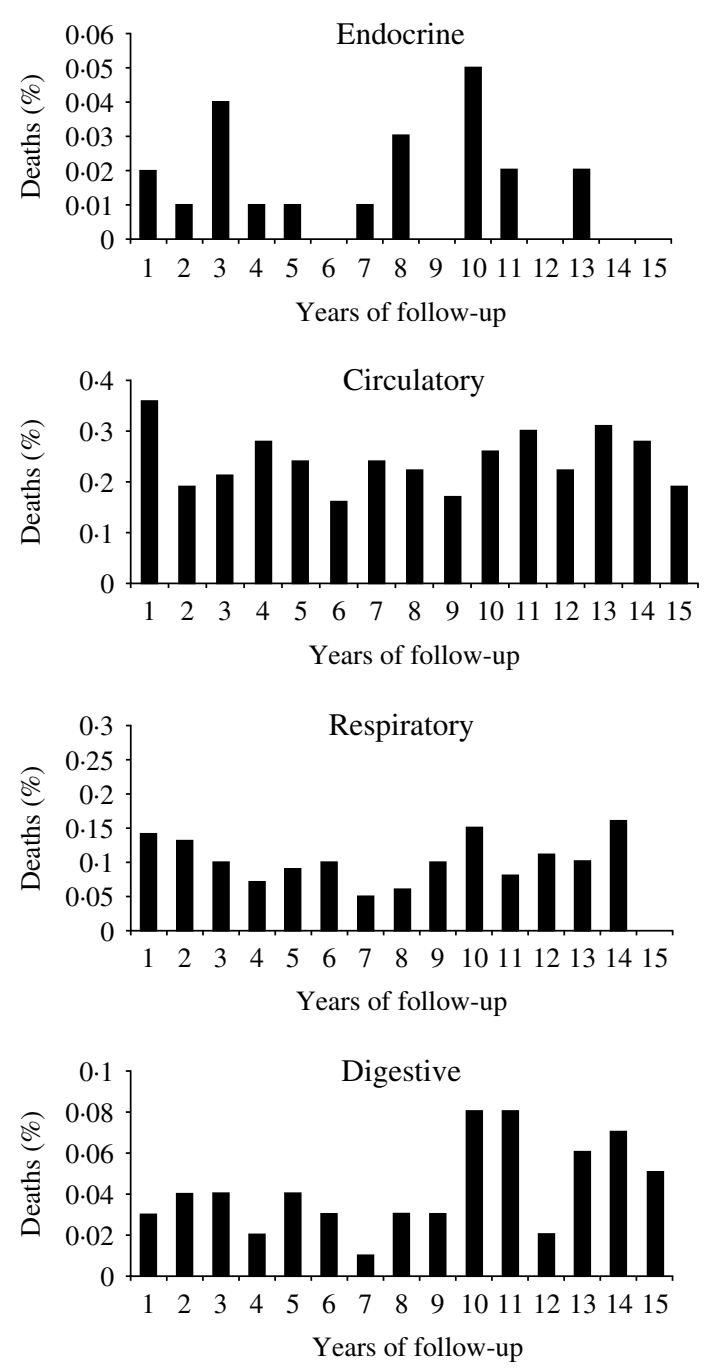

FIG. 1. Timing of death for specific natural causes.

although in that study, which had a much shorter follow-up period and was based on a considerably smaller sample, the risk was greater in females than males (Hawton \& Fagg, 1988). The level of excess risk compared with the general population was similar to that found in a previous study from the USA, although the follow-up period in that study was shorter (Pederson et al. 1975). However, it was considerably lower than in similar studies from Denmark (Nordentoft et al. 1993) and Finland (Ostamo \& Lönnqvist, 2001). This difference probably in part reflects the relatively older 

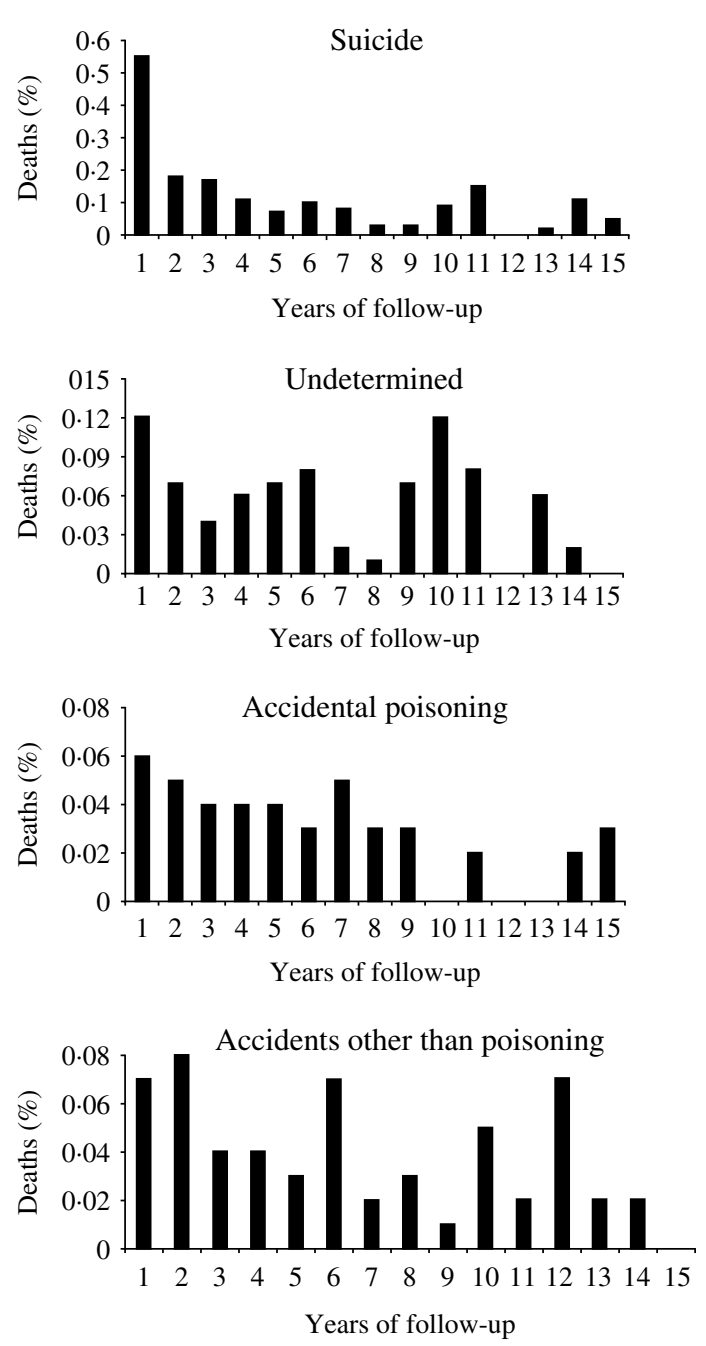

FIG. 2. Timing of death for specific external causes.

age of the Scandinavian patients. In keeping with the gender difference in risk found in the present study, in all three previous studies males had a higher overall risk of dying than females.

\section{Deaths due to suicide and related causes}

It is already well established that DSH patients have a considerably elevated risk of dying from suicide and also from causes that are likely to be suicides (e.g. undetermined cause, accidental poisoning) (Nordentoft et al. 1993; Hawton \& Fagg, 1988; Harris \& Barraclough, 1998). The number of suicides in this DSH population was approximately 17 times that which would be expected in the general population. The ratio of observed to expected numbers of suicides was particularly high in females. However, absolute rates of suicide following DHS in males considerably exceed those found in females (Hawton et al. 2003 b). This apparently contradictory finding is due to the far lower general population rates of suicide in females. There was also a greatly elevated risk of death in the 'undetermined cause' category compared to the general population, comparable to the excess found for suicide. This provides further support for combining this category of death verdict with suicide verdicts in epidemiological investigations of suicide (Linsley et al. 2001). A similar excess risk was also found for accidental poisonings, again supporting the policy of including this category of death verdict in epidemiological studies of suicide (Hawton et al. $2001 c, 2003 b$ ). The excess in deaths from symptoms, signs and ill-defined conditions might also reflect some misclassified suicides.

Deaths due to suicides and those with open verdicts were most frequent in the first few years of follow-up. Deaths due to accidental poisoning were also most frequent during the first half of the follow-up period, which is in keeping with their often being deliberate self-poisoning (i.e. unidentified suicides).

\section{Deaths due to physical illnesses}

DSH patients appear to have an increased likelihood of dying from most physical illnesses. There is a question about whether this relates specifically to DSH (which is clearly relevant in the suicide findings), or whether it reflects the known association of certain physical conditions with psychiatric disorders, the latter explaining the association with DSH (Hendin, 1999; Stenager \& Stenager, 2000; Lawrence et al. 2003). Using data from the National Comorbidity Survey in the USA, Goodwin et al. (2003) showed a relationship between physical illness and suicide attempts after controlling for psychiatric disorder. This was particularly so for lung disease, gastro-intestinal ulcers and acquired immunodeficiency syndrome (AIDS).

Another possible explanation for the association between physical illnesses and DSH is the excess in DSH patients of certain behaviours that increase the risk of both DSH and physical 
disorder. These include alcohol abuse (Murphy, 2000), aggression, and impulsivity or risk taking (Mann et al. 1999). Another explanation might be that the presence of physical illness in itself increases risk of suicidal behaviour, perhaps due to depression or as a reaction to incapacity and pain (Stenager \& Stenager, 2000). A further possible explanation is the inverse social class gradient (Hawton et al. 2001 b) and socioeconomic deprivation (Gunnell et al. 1995; Hawton et al. 2001a) known to characterize DSH patients, as many physical disorders are more common in socially disadvantaged groups (White et al. 2003). While social class is a likely factor, the excess of deaths from physical illness is considerably greater than would be expected if it were due to social class alone.

This is one of several studies to have shown an excess in deaths from neurological and respiratory disorders in DSH patients (Pederson et al. 1975; Hawton et al. 1988; Nordentoft et al. 1993). Part of the excess in deaths from neurological causes is due to epilepsy, a condition known to have an association with both DSH (Mackay, 1979; Hawton et al. 1980) and suicide (Barraclough, 1981). Suicide has also been linked to multiple sclerosis (Harris \& Barraclough, 1994), especially in younger patients (Stenager et al. 1992). We found only limited evidence of greater mortality from this cause in female DSH patients, although the number of cases was very small. The fact that deaths due to tumours were no more common than expected in the DSH patients is surprising given the known association between smoking and suicidal behaviour (Miller et al. 2000; Malone et al. 2003), although the excess in deaths from respiratory conditions may reflect this association. This might also explain the excess of deaths due to circulatory causes, which was also found in the earlier study from Oxford (Hawton \& Fagg, 1988). In that study the absence of an excess of deaths due to digestive disorders was highlighted as surprising, given the extent of alcohol abuse in this population (Murphy, 2000; Hawton et al. 2003a), but was attributed to the relatively short follow-up period. In the present study, with its much longer follow-up, an excess in deaths due to digestive conditions has been shown clearly, in keeping with the finding of Nordentoft et al. (1993) in their 10-year follow-up study of Danish suicide attempters. In addition, the escalation in risk of death from digestive conditions the longer the follow-up period is in keeping with the course of alcohol-related gastro-intestinal disorders. Inspection of individual death certificates indicated that many of these deaths were from specific conditions that are common in alcohol abusers, such as hepatic cirrhosis and gastric ulcers.

Most of the excess in deaths from endocrine disorders was due to diabetes. However, the excess in this study only just attained statistical significance. In their review of studies of medical disorders and suicide, Harris \& Barraclough (1994) did not find evidence of an association of diabetes with suicide, although Kyvik et al. (1994) did in a single study. Goodwin et al. (2003) found no association between diabetes and attempted suicide.

The reasons for the excess of deaths due to diseases of the skin, musculoskeletal and connective tissue disorders, both of which were marked in males, are unclear.

There were an excess of deaths in both sexes because of accidents not due to poisoning, confirming the findings of previous studies (Pederson et al. 1975; Hawton \& Fagg, 1988; Nordentoft et al. 1993). This was not primarily due to a greater than expected number of motor vehicle accidents but to more accidents of other types. An excess number of deaths by accidents was also found in the follow-up study of Finnish suicide attempters (Ostamo \& Lönnqvist, 2001), but there was no differentiation between poisoning and non-poisoning accidents in that study. The similarity of the timing of non-poisoning accident deaths to those involving poisoning suggests that some of these would also have been due to suicidal behaviour.

Violence and aggression are relatively common in DSH patients (Mann et al. 1999; Hawton et al. 2003a). We have reported elsewhere that being a victim of violence is also common and increasing in DSH patients (Hawton et al. 2003a). The excess in homicide deaths in the male DSH patients in this study is in keeping with this.

\section{Methodological issues}

A strength of this study is that we have been able to follow-up most members of a very 
large consecutive sample of DSH patients. In addition, the long follow-up period has allowed detection of any increased risk of death from conditions that might be due to the consequences of long-standing patterns of unhealthy behaviour linked to DSH, such as smoking and alcohol abuse. Use of annual general population death rates for the entire study period within gender and age subgroups has permitted generation of accurate estimates of expected numbers of deaths. A limitation of the study is that the sample of DSH patients was only from one general hospital. However, the characteristics of the patients presenting to this hospital have been shown to be similar to those from elsewhere in the UK (Platt et al. 1988). In addition, reliance solely on the underlying cause of death recorded on death certificates may mean that some associations between DSH and physical disorders that may also have contributed to mortality may have been missed.

\section{CONCLUSIONS}

There is clearly a considerable risk of death in DSH patients from causes in addition to suicide and probable suicide. The reasons may vary according to category of death. The excess risk of deaths from physical disorders should alert clinicians dealing with DSH patients to be vigilant for signs of physical illness. The excess deaths due to accidents and homicide warrant further investigation. Deaths from all causes should be included in assessments of health-care costs associated with DSH.

\section{ACKNOWLEDGEMENTS}

This study was funded by the National Health Service Executive for England. Keith Hawton is also funded by the Oxfordshire Mental Healthcare Trust. We thank the staff of the Office for National Statistics for England and Wales, the General Register Office for Scotland and the Central Services Agency in Northern Ireland for their assistance with this project, and Douglas Altman for commenting on the manuscript. Staff at the Department of Psychological Medicine at the John Radcliffe Hospital in Oxford, and Elizabeth Bale and Alison Bond, assisted with the original identification of the patients included in the study.

\section{DECLARATION OF INTEREST}

None.

\section{REFERENCES}

Barraclough, B. (1981). Suicide and epilepsy. In Epilepsy and Psychiatry (ed. E. H. Reynolds and M. R. Trimble), pp. 72-76. Churchill Livingstone: Edinburgh.

De Leo, D., Scocco, P., Marietta, P., Schmidtke, A., Bille-Brahe, U., Kerkhof, A. J. F. M., Lönnqvist, J., Crepet, P., Salander-Renberg, E., Wasserman, D., Michel, K. \& Bjerke, T. (1999). Physical illness and parasuicide: evidence from the European Parasuicide Study Interview Schedule (EPSIS/WHO-EURO). International Journal of Psychiatry in Medicine 29, 149-163.

Goodwin, R. D., Marusic, A. \& Hoven, C. W. (2003). Suicide attempts in the United States: the role of physical illness. Social Science and Medicine 56, 1783-1788.

Gunnell, D., Peters, T., Kammerling, R. \& Brooks, J. (1995). Relation between parasuicide, suicide, psychiatric admissions, and socioeconomic deprivation. British Medical Journal 311, 226-230.

Harris, E. C. \& Barraclough, B. (1998). Excess mortality of mental disorder. British Journal of Psychiatry 173, 11-53.

Harris, E. C. \& Barraclough, B. M. (1994). Suicide as an outcome for medical disorders. Medicine 73, 281-296.

Hawton, K. \& Fagg, J. (1988). Suicide, and other causes of death, following attempted suicide. British Journal of Psychiatry 152, 359-366.

Hawton, K., Fagg, J. \& Marsack, P. (1980). Association between epilepsy and attempted suicide. Journal of Neurology, Neurosurgery and Psychiatry 43, 168-170.

Hawton, K., Fagg, J. \& Simkin, S. (1988). Female unemployment and attempted suicide. British Journal of Psychiatry 152, 632-637.

Hawton, K., Fagg, J., Simkin, S., Bale, E. \& Bond, A. (1997). Trends in deliberate self-harm in Oxford, 1985-1995. Implications for clinical services and the prevention of suicide. British Journal of Psychiatry 171, 556-560.

Hawton, K., Harriss, L., Hall, S., Simkin, S., Bale, E. \& Bond, A. $(2003 a)$. Deliberate self-harm in Oxford, 1990-2000: a time of change in patient characteristics. Psychological Medicine 33, 987-996

Hawton, K., Harriss, L., Hodder, K., Simkin, S. \& Gunnell, D. $(2001 a)$. The influence of the economic and social environment on deliberate self-harm and suicide: an ecological and personbased study. Psychological Medicine 31, 827-836.

Hawton, K., Harriss, L., Simkin, S., Bale, E. \& Bond, A. (2001 b) Social class and suicidal behaviour: the associations between social class and the characteristics of deliberate self-harm patients and the treatment they are offered. Social Psychiatry and Psychiatric Epidemiology 36, 437-443.

Hawton, K., Townsend, E., Deeks, J. J., Appleby, L., Gunnell, D., Bennewith, O. \& Cooper, J. (2001c). Effects of legislation restricting pack sizes of paracetamol and salicylates on self poisoning in the United Kingdom: before and after study. British Medical Journal 322, 1203-1207.

Hawton, K., Zahl, D. \& Weatherall, R. (2003b). Suicide following deliberate self-harm: long-term follow-up of patients who presented to a general hospital. British Journal of Psychiatry 182, 537-542.

Hendin, H. (1999). Suicide, assisted suicide, and medical illness. Journal of Clinical Psychiatry 60 (Suppl. 2), 46-50.

Kyvik, K. O., Stenager, E. N., Green, A. \& Svendson, A. (1994). Suicides in men with IDDM. Diabetes Care 17, 210-212. 
Lawrence, D. M., Holman, C. D. J., Jablensky, A. V. \& Hobbs, M. S. T. (2003). Death rate from ischaemic heart disease in Western Australian psychiatric patients 1980-1998. British Journal of Psychiatry 182, 31-36.

Linsley, K. R., Schapira, K. \& Kelly, T. P. (2001). Open verdict v. suicide - importance to research. British Journal of Psychiatry 178, 465-468.

Mackay, A. (1979). Self-poisoning - a complication of epilepsy. British Journal of Psychiatry 134, 277-282.

Malone, K. M., Waternaux, C., Haas, G., Cooper, T. B., Li, S. \& Mann, J. J. (2003). Cigarette smoking, suicidal behaviour, and serotonin function in major psychiatric disorders. American Journal of Psychiatry 160, 773-779.

Mann, J. J., Waternaux, C., Haas, G. L. \& Malone, K. M. (1999). Toward a clinical model of suicidal behavior in psychiatric patients. American Journal of Psychiatry 156, 181-189.

Miller, M., Hemenway, D. \& Rimm, E. (2000). Cigarettes and suicide: a prospective study of 50,000 men. American Journal of Public Health 90, 768-773.

Murphy, G. E. (2000). Psychiatric aspects of suicidal behaviour: substance abuse. In The International Handbook of Suicide and Attempted Suicide (ed. K. Hawton and K. Van Heeringen), pp. 135-146. Wiley: Chichester.

Nordentoft, M., Breum, L., Munck, L. K., Nordestgaard, A. G., Hunding, A. \& Laursen Bjaeldager, P. A. (1993). High mortality by natural and unnatural causes: a 10 year follow up study of patients admitted to a poisoning treatment centre after suicide attempt. British Medical Journal 306, 1637-1641.
Ostamo, A. \& Lönnqvist, J. (2001). Excess mortality of suicide attempters. Social Psychiatry and Psychiatric Epidemiology 36 29-35.

Pederson, A. M., Tefft, B. M. \& Babigian, H. M. (1975). Risks of mortality of suicide attempters compared with psychiatric and general populations. Suicide 5, 145-157.

Platt, S., Hawton, K., Kreitman, N., Fagg, J. \& Foster, J. (1988) Recent clinical and epidemiological trends in parasuicide in Edinburgh and Oxford: a tale of two cities. Psychological Medicine 18, 405-418.

Sakinofsky, I. (2000). Repetition of suicidal behaviour. In The International Handbook of Suicide and Attempted Suicide (ed. K. Hawton and K. Van Heeringen), pp. 385-404. Wiley: Chichester.

Stenager, E. N. \& Stenager, E. (2000). Physical illness and suicidal behaviour. In The International Handbook of Suicide and Attempted Suicide (ed. K. Hawton and K. Van Heeringen), pp. 405-420. Wiley: Chichester.

Stenager, E. N., Stenager, E., Koch-Henriksen, N., BronnumHansen, H., Hyllested, K., Jensen, K. \& Bille-Brahe, U. (1992). Multiple sclerosis and suicide. An epidemiological study. Journal of Neurology, Neurosurgery and Psychiatry $\mathbf{5 5}$ $542-545$.

White, C., van Garlen, F. \& Chow, Y. H. (2003). Trends in social class differences in mortality by cause, 1986 to 2000. Health Statistics Quarterly 20, 25-37.

WHO (1997). International Classification of Diseases (9th revision, vol. 1, 9th edn). World Health Organization: Geneva. 